\title{
Pnömatik Hassas Ekim Makinalarında Tohumların Tutulmasına Etkili Bazı Parametrelerin Etki Derecelerinin Belirlenmesi
}

\author{
Ali Ihsan ACAR ${ }^{1}$
}

Geliş Tarihi : 29.06.2001

\begin{abstract}
Özet: Pnömatik hassas ekim makinaları kullanılarak, tohumlar tek tek ekilebilmekte, tohumluktan ve ekim sonrası seyreltme gibi işlemlerde ișçillkten tasarruf sağlanabilmektedir. Bu makinalarda ekim kalitesine etkili en önemli faktör, vakum ve ekici delikfi plakaların çevre hızları olmaktadır. Ekici düzenin en önemli elemanı olan delikli plakadaki deliklerin çapı ve sayısı, tohumlann fizikomekanik ozelliklerine ve ekim tekniğine uygun olarak belirlenmektedir.

Bu çalışmada, mısır, ayçiçeği, soya, kaplanmış ve kaplanmamış şekerpancarı tohumlarının hangi vakum değerinde, ekici delikli plakanın hangi delik çaplarında ve çevre hızı değerinde deliklerde tutulabileceğinin belirlenmesi amaçlanmıştır.

Bu makinalar için geçerli olan llerleme hizı değerleri ile tohumlanin sıra uzeri ekilme uzaklıkları ve fizikomekanik özelilikleri belirlenmiștir. Uygulamada kullanılan makinaların, tekerlek çapı, hareket iletim oranı ve ekici delikli plaka çapı gibi konstruktif değerleri kullanıımıștır. Denemelerde; tohumların tutulduğu deliklerin çaplari, $1.5,2,2.5,3,3.5,4,4.5,5,5.5,6,6.5$ ve $7 \mathrm{~mm}$, vakum seviyeleri $-4,-6,-8,-10,-12$ ve $-14 \mathrm{kPa}$ ve ekici delikli plakanin çizgisel hiz değerleri $0.25,0.38,0.55$ ve $0.79 \mathrm{~m} / \mathrm{s}$ olarak alınmiştır.

Sonuç olarak; tohumlar belirli delik çaplarında vakum seviyesi ve ekici delikli plaka çizgisel hızının tüm seviyelerinde delikte tek tek tutulmuştur, Bu uygun değerier dışında, daha küçük delik çaplarında genellikle, yolksek vakum ve düşak ekici delikli plaka çizgisel hiz değerlerinde tohumlar deliklerde tek tek tutulabilmektedir. Ancak, vakum değeri düşárüldūğônde ve delikli plakanin yüksek çizgisel hız değerierinde tohumlarin deliklerde tutuimaları güçleşmektedir. Delik çapı boyüdăkçe de tohumların tek tek tutulma oranları azaimakta, tohumiar ya iki ve daha fazla tutulmakta ya da emme hattının içerisine girmektedirler.
\end{abstract}

Anahtar Kelimeler: pnömatik hassas ekim makinası, ekici delikji plaka, vakum, çizgisel hız, delik çapı

\section{Determination of the Effects of Some Parameteres on Picked up in Precision Pneumatic Drills}

\begin{abstract}
Precision pneumatic drills is used in seed singling and it provides a decrease in the labour in thinning operation, Vacuum and peripheral velocity of seed metering device are two important factors which affect the quality of seeding. Hole diameters and numbers of holes on rotate seed metering plate are determined according to the physicomechanical properties of seeds and the distance of seed in the row.

The aim of this research is, to determine the suitable vacuum level, hole diameters and peripheral velocity of rotate metering plate device for corn, sunflower, soybean, covered and uncovered sugarbeet seeds.

In this study, proper forward speed of the precision pneumatic drills, distance of seed in the row and physicomechanical properties had been found for the mentioned seeds. Constructional values such as the diameter of wheel, transmititon ratio and diameter of rotate metering plate had been used to calculate linear velocity of rotate metering plate. The hole diameters were $1.5,2,2.5,3,3.5,4,4.5,5,5.5,6,6.5$ and $7 \mathrm{~mm}$; vacuum levels were $-4,-6,-8,-10,-12$ and $-14 \mathrm{kPa}$; the linear velocity of rotate metering plate were $0.25,0.38$, 0.55 and $0.79 \mathrm{~m} / \mathrm{s}$ in trials.

As a result of this, the seeds had been holded in the significant hole diameterson the all vacuum and all linear velocity. In addition to this Besides the seeds could be holded as a single seed which is smaller than the hole diameters generally at the high vacuum level and low linear velocity level, however the seeds could not be holded in low vacuum levels and high linear velocities. The amount of single seeds decrease when the bigger hole diameter was used, since the seeds either holded multiply or run to the vacuum line.
\end{abstract}

Key Words: precision pneumatic drills, rotate metering plate, vacuum, linear velocity, hole diameter

\section{Giriş}

Mekanik hassas ekim makinalarında, tohumlar ile ekici duzende yer alan yuvalar ya da delikler arasında sorunlar ortaya çıkmaktadır. Ayrıca, tohumların yuvalara girme olasılığı etkilendiğinden, ilerleme hızında belirli değerlerin azerine çıkılamamaktadır. Mekanik hassas ekim makinalarında mevcut bu soruniarın giderilebilmesi amacıyla pnömatik hassas ekim makinaları geliştirilmiştir.
Bu makinalarla; tohum kullanım miktarı örneğin marulda \% 90 'a kadar, seyreltmede işgücū gereksinimi ise \% 45'e kadar azaltilabilmekte (Giannini ve ark 1967); ayrica;

- Değişik boyutlarda tohumiar ekilebilmekte,

- Monogerm tohumlar ekilebilmekte,

- Daha yưksek hızlarda çalışılabilmekte,

\footnotetext{
${ }^{1}$ Ankara Üniv. Ziraat Fak. Tarım Makinaları Bölämü-Ankara
} 
- Ekici düzen değiştirilmeden çok geniş sıra Qzer uzaklıklarda ekim işlemi yapılabilmektedir (Gokçebay 1986)

Mekanik hassas ekim makinalarina ek olarak bu makinalarda, kuyruk milinden hareket alan bir hava akımı kaynag̈ı bulunmaktadır (Ülger ve ark. 1996). Sıra arası uzaklıklara bağlı olarak, çapa bitkisi tohumlarının ekiminde kullanilan ve pnơmatik ilkeye göre çalışan ekim makinelarında, delikli plakali ya da diskli ekici düzenler kullanilmaktadır (Onal 1995). Tohumların fizikomekanik ozzelliklerine ve agroteknik isteklerine bağlı olarak, delikli plaksdaki delik çapi ve delik sayısi değişiklik göstermektedir.

Vakum ilkesine göre çalıșan doşey delikii plakalı ya da diskll pnömatik hassas ekici düzenlerde ekim kalitesine;

- Ekici plakanin çevre hizi,

- Ekici plakadaki dellklere tohumu younlendiren ve tohum hizini plaka hizina senkronize eden kanatli çarkın bulunması,

- Vakum basinci etkili olmaktadir (Onal 1995),

Pnömatik hassas ekim makinalarında ilerieme hizı degerleri; tohuma, vakum degerine, toprak yapısına ve ekici delikli plakadaki delik sayısına bağlı olarak degis. mekle birlikte; $5-9 \mathrm{~km} / \mathrm{h}$ arasinda olabilmektedir Anonim 1999, (Anonim 1987). Vakumlu hassas ekim makinalarında $12 \mathrm{~km} / \mathrm{h}$ ilerleme hizinda, en onemli etken olan tek dane yakalama oraninin \% 50'nin altına dusşmemesi sağlanabilmektedir. Ancak, ekici dúzende yer alan delikli plakanın çevre hızı, tohum dusşme yolksekligii, çizi açıcı ve kapatıcı organin tipine baŏhı olarak, ilerleme hrzı $7-8 \mathrm{~km} / \mathrm{h}$ 'in Uzerinde olmamalidir (Onal 1995).

Acar ve ark (1993), yaptıkları çalışmada, tasarladiklari tamburiu tip pnomatik ekici dozen ile havug tohumlarınin değişik sıra ozeri uzaklıklar için sıra uzeri dağılim dözganloğäna; tohumların tekleme, boş geçme, ikizleme ve çoklarna yüzdelerini araștırmışlardir. Ekici tambur cevre hizl ve tohumlari kontrol ettikleri bandin llerleme hızi değerleri arasındaki ilişkilerden yarartanarak elde ettikleri regresyon denklemlerini ve bellitme katsayısı değerlerini vermişlerdir. Ekici dazenin en etkin çalıştığı bölge, ekici tambur lle ilerleme hızlarınin en dūşỏk olduğu değerler olarak saptanmıştır. Tambur cevre hizı değerlerinin artmasina bağlı olarak, sira ozeri dağilim düzünluagünün bozulduğu, teklemenin daștağo, buna karşın boş geçme ve ikizlemenin arttığı goralmaştar.

Shafil ve ark. (1991), çalışmalarında hava memeli tohum tekleyici uzerinde çalișmışlardır. Araştımada, materyal olarak domates tohumların kullanarak $180 \mathrm{~mm}$ çapında ekici plaka diskini denemişlerdir. Calışmalarını, OC farklı vakum seviyesinde $(-2.44,-3.42$ ve $-4.40 \mathrm{kPa})$, ac farkli ekiei plaka cizgisal hizında (63.6, 130.7 ve 204.3 $\mathrm{mm} / \mathrm{s}$ ), tekleyici hava memesinin oç değişik konumunda ve uc farkiı ufleme basıncı değerinde gerçekleştirmişlerdir. Bir diger tip makinayı da: $-3.7,-4.97$ ve $-6.21 \mathrm{kPa}$ vakum değerlerinde; $71,6,119.4$ ve $167 \mathrm{~mm} / \mathrm{s}$ ekici plaka çizgisel hızında denemişlerdir:

Vakum ilkesine göre çalışan pnömatik hassas ekim makinalarında işletme basıncı değeri, kesintisiz ve ayni seviyede olmalıdır. Bu değer çalışma sirasinda, $-5.9 . .-8.8$ $\mathrm{kPa}$ 'ın aitına daşmemelidir. Misır için bu değer $-8.8 \mathrm{kPa}$ olarak verilebilmektedir (Onal 1995). Ișletme vakum basincı değerleri, yonca tohumları için $-17 \mathrm{kPa}$ (Sweetman 1957), şekerpancarı tohumlan için $-3 \mathrm{kPa}$ ve fasulye tohumları için -15 kPa (Hammond 1965) olarak onterilebilmektedir, Kụçók tohumlar için ise bu değerler, maydanoz ve marulda $-1.47 . .-2.44 \mathrm{kPa}$; havuc ve haşhaşta $1,96 \ldots-2.93 \mathrm{kPa}$; lahana, turp ve biberde $-3.9 \ldots-5.9$ kPa olabilmektedir (Acar ve ark. 1994).

Guarella ve ark. (1996), kaçük sebze tohumlarından domates tohumları ile $0.3,0.5,0.7$ ve $0.9 \mathrm{~mm}$ delik çapında ekici plakalarla yaptıklari ve emme yoksekliklerini belirledikleri çalışmada; vakum basıncı değerini $0 . .-80$ $\mathrm{kPa}$ arasında tutmuşlardır. Sonuçta vakum değeri -20 kPa'a kadar olduğunda tohum tutulma yáksekliği değerlerindeki artışın onemli olduğunu, ancak -20 kPa'dan fazla vakum değerinin tohumlarin tutulma yüksekliğinde onemli bir gelişme sağlamayacağı gibi, gereksiz enerji kullanımına ve ekimin kalltesinl etkilemeksizin yoksek giderlere neden olacağını vurgulamışlardır.

Vakum etkisiyle çalışan dūșey delikil plakalı pnomatik duzende, misır tohumu için $-10.8 \mathrm{kPa}$ ve -14.7 $\mathrm{kPa}$ işletme basıncı degerlerinde, plaka hızı $\left(V_{p}\right)$ ve makina llerleme hızının $\left(V_{m}\right)$ tek dane yakalama oranına (TDYO) etkisi Şekil 1'de górülmektedir.

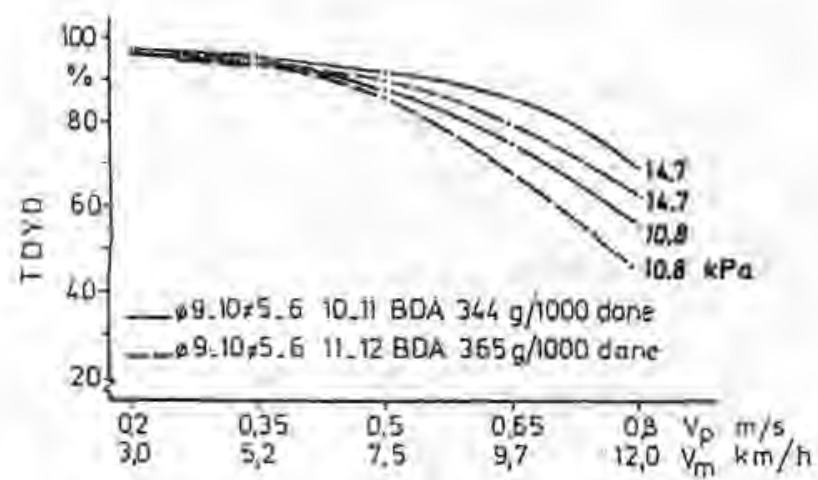

Sekil 1. Duşey delikil plakalı pnómatik dözende, musir tohums için $-10.8 \mathrm{kPa}$ ve $-14.7 \mathrm{kPa}$ işletme basinci değerlerinde, plaka hizi $\left(V_{P}\right)$ ve makina ilerleme hizinin $\left(V_{m}\right)$ tek dane yakalama oranina (TDYO) etkisi (Onal 1985)

Şekil 1'de goroldago gibi, $7.5 \mathrm{~km} / \mathrm{h}$ makina ilerleme hizı değerine $(0.5 \mathrm{~m} / \mathrm{s}$ disk çevre hızı) kadar tek dane yakalama orani (TDYO) \% 90-95 oraninda iken, ilerleme hizı $12 \mathrm{~km} / \mathrm{h}^{\prime} e$ (disk çevre hızı $0.8 \mathrm{~m} / \mathrm{s}$ ) çıktığında, -14.7 $\mathrm{kPa}$ vakum değerinde TDYO $\% 75^{\prime}$ e kadar düșmektedir.

Pnomatik hassas ekim makinalarinda tohumların, ekici dozende yer alan delikli plakalarda vakum etkisiyle tek tek tutulmas! istenmektedir. Bundan olabilecek sapmalar, deliklerde hic tohum tutulmaması ya da 1 adetten fazla tohum tutulmasidir. Bunlann lkisi de istenmeyen ozellikler olmasına karşın, her delikte 2 ya da daha fazla tohum tutulmasi, ekici dózende bulunan tekleyicinin 
etkinliği açısından tohumların hiç tutulamamasına yeğlenebilmektedir.

Bu çalışmada; vakum etkisiyle çalıșan pnomatik hassas ekim makinaları ile ekilen bazı tohumların, hangi delik çapı, hangi vakum dazeyi ve hangi delikli plaka çevre hızı, dolayısıyla makina ilerleme hizı değerlerinde tutulabileceginin belirlenmesi ve uygulamaya aktarilabilir verilerin ortaya koyulması amaçlanmıştı.

\section{Materyal ve Yöntem}

Denemelerde; kaplanmış ve kaplanmamıs şeker pancarı, soya, ayçiçeği ve mısır tohumları kullanılmıștır. Tohumlara ilişkin fizikomekanik ozellikler Çizelge 1'de verilmiştir.

Denemeler Ankara Universitesi Ziraat Fakoltesi Tarım Makinaları Bölümü Kadayıfçılar Atölyesi'nde gerçekleştirilmiştir. Ekici delikli plaka çizgisel hiz değerlerine uygun hiz değerlerinde hareket edebilen, ayarlanabilirlik ve hassas ölçme ózelliklerinden dolayı atölyede mevcut olan vargel tezgahindan yararlanilmıştır.

Vargel tezgahına bağlanmiş biçimde ölçme sisteminin şematik görünuşa Şekil $2^{\prime}$ de verilmiştir.

Ölçme sisteminde yer alan bir elektrik motoruna direkt bağlı fan döndärälmektedir. Fan döndärüldogăande, hava, emme ağzına yerleştirilen delikli plaka azerinden, vakum deposuna, oradan da fana dogru emilmektedir. Vakum deposu sayesinde, vakum hattındaki basincin düzeyinin surekli ayni kalması sağlanmaya çalışilmiştir. Vakum deposu esneyebilir bir boru ile emme plakasının yerleştirildiği yuvarlak kesitli galvanizli boruya kelepçe lle bağlanmiştır. Emme hatında, hava hızinda değişmeler olmaması için yuvarlak boru seçilmiştir. Bu bağlantı yerine, bazı tohumların boyutiarınin o anki denemede kullanılan delikli plaka çapından kaçak olması sonucu vakum hattında emilip, küresel vana, vakummetre gibi elemanlarda tıkanmalara neden olmaması için bir filtre yerleștirilmiştir. Emme hattı üzerinde $0 . .-16 \mathrm{kPa}$ değer aralığında ólçŭm yapabilen bir vakummetre ile emme hattındaki vakumu ayarlamaya yarayan bir kuresel vana bulunmaktadır. Emme ağzının yer aldığı boru, bir kelepçe ile vargel tezgahının ileri geri hareket eden kafasına bağlanmıştır. Emme ağzının kesit görūnūşo Şekil 3'de verilmiştir. Emme ağzının tam altına gelecek şekilde $5 \mathrm{~cm}$ genişliğinde 1 mm'lik sacdan bir kanal yapılmıştır. Kanal, vargel tezgahının tablası ëzerine sabitlenmiştir ve aşaŏı yukarı hareket ettirilebilmektedir.

Emme ağzında, değişik delik çaplarındaki plakaların kolayca sokalap değiştirilebilmesine olanak veren vidalı bir yapı oluşturulmuştur. Plakaların dış çapları $22 \mathrm{~mm}$ olarak belirlenmiştir ve delikler bu dairenin tam ortasına gelecek şekilde merkezlenmiştir. Delikli plakalardaki delikler değişik tohum boyutlarına uygun olarak 12 farkiı çapta $(1.5,2,2.5,3,3.5,4,4.5,5,5.5,6,6.5$ ve $7 \mathrm{~mm})$ seçilmişlerdir. Delikli plaka, uygulamada kuilanilan çelik malzemeden yapilarak tohum ile plaka arasındaki sürtünme katsayısının etkisi aynı tutuımuştur.
Çizelge 1. Denemelerde kullanilan tohumiarın fizikomekanik ozellikderi

\begin{tabular}{|c|c|c|c|c|c|}
\hline \multirow[t]{2}{*}{ Tohum } & \multirow{2}{*}{$\begin{array}{c}1000 \\
\text { dane } \\
\text { ağ } \\
\text { (g) }\end{array}$} & \multirow{2}{*}{$\begin{array}{c}\text { Hacim } \\
\text { ağırlığ! } \\
(\mathrm{kg} / \mathrm{dm} \\
)\end{array}$} & \multicolumn{3}{|c|}{ Ortalama dane boyutlan (mm) } \\
\hline & & & Uzunluk & Genişlik & Kalınlık \\
\hline $\begin{array}{c}\text { Şekerpancan } \\
\text { (kaplanmis) }\end{array}$ & 24 & 0.47 & 4.0 & 4.0 & 3.0 \\
\hline $\begin{array}{l}\text { Şekerpancan } \\
\text { (kaplanmamis) }\end{array}$ & 14 & 0.35 & 4.5 & 4.0 & 2.0 \\
\hline Soya & 154 & 0.79 & 7.0 & 6.5 & 5.0 \\
\hline Misir & 404 & 0.82 & 10.0 & 8.0 & 6.0 \\
\hline Avcriceği & 160 & 0.39 & 14.0 & 9.0 & 5.0 \\
\hline
\end{tabular}

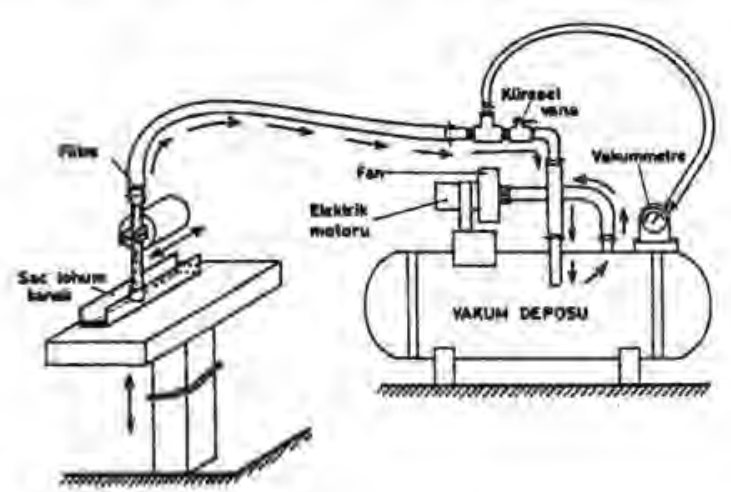

Şekil 2. Olçme sisteminin șernatik görünüşu

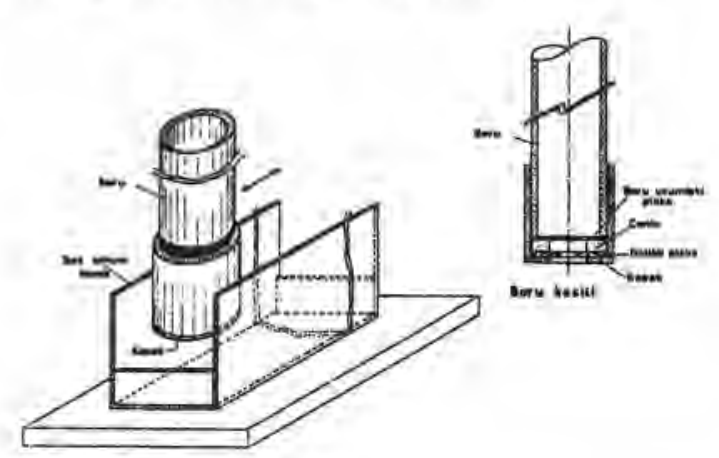

Şekil 3. Emme ağzınin kesiti

Vakumlu ekim makinalarında, ekici dazende yer alan delikli plaka, hareketini makina uzerinde bulunan ve toprak ozerinde ilerleyen tekerlekten aimaktadır. Dolayısıyla delikli plakanın devri, makinanın ilerleme hızına bağlı olarak değişmektedir. Tohumun istenen sıra üzeri uzaklığa ekilmesi ise delikli plaka azerinde yer alan delik sayısına göre belirlenmektedit. Buna göre; önce delikli plakadaki delik sayısı belirlenmekte, daha sonra makina üzerinde bulunan ve delikli plakaya hareket veren tekerleğin çapı, bu tekerlek ile delikli plaka arasında hareket iletimini sağlayan dişlilerin iletim oranı dikkate alınarak, delikli plakanın uygun devir sayısı bulunabilmektedir. Uygula-mada kullanılan uygun ilerleme hizı ve buna bağlı olarak devri değișen tohum ekici delikli plaka çevre hızı değerleri, gerek literatür değerlerinden gerekse bu makinaların katalog bilgilerinden yararlanilarak saptanmış-tir (Çizeige 2). 
Çizelge 2'de son sütunda yer alan ekici delikli plaka çizgisel hiz değerlerinin elde edilebilmesi için öncelikle pnömatik ekim makinalan içìn uygun ilerleme hızı değerleri $\left(V_{k}\right) 5,6,7,8,9 \mathrm{~km} / \mathrm{h}$ olarak tespit edilmiştir. Makinanin delikli plakaya hareket ileten tekerleğinin çap değerinden yararlanilarak, tekerlek devir sayısı (nT) bulunmuştur. Daha sonra, araștırmada materyal olarak kullanılan misır, soya fasulyesi, ayçiçeği ve şekerpancan tohumlarının uygulamada hangi sıra üzeri uzaklıklara, hangi çaptaki ve kaç delik sayısındaki delikli plakalarla ekildiği saptanmıştır. Bu değerlerden ve makinaların katalog değerlerinden, delikli plakalar ile makinanın hareket veren tekerleği arasındaki jletim oran (i) belirlenmiştir. Bu iletim oranından ekici düzen delikli plakasının devrinin (nD) bulunmasında yararlanılmiştır. Sonuçta, bulunan devir sayısına bağlı açısal hız (w) değeri, çizgisel hız (V) değerine dónaştüraimüştar.

Ekici delikli plaka azerindeki bir deliğin en alt konumda çizgisel hız değeri Şekil 4'de gösterilmiştir. Şekil 4'de, Çizelge 2 'de yer alan $7 \mathrm{~km} / \mathrm{h}$ ilerleme hızında şekerpancarı tohumlarının $15.4 \mathrm{~cm}$ sıra azeri uzaklığa ekimi için ekici plakanın $45.4 \mathrm{~d} / \mathrm{d}$ ile dönmesi durumunda açısal hız $4.75 \mathrm{rad} / \mathrm{s}$ iken, emme noktasındaki $0.55 \mathrm{~m} / \mathrm{s}$ çizgisel hız değeri gösterilmiştir. Burada, vektörel olarak $1 \mathrm{~m} / \mathrm{s}=50 \mathrm{~mm}$ ólçeğinde alınmıştır.

Çizelge 2 incelendiğinde,ekici düzen delikli plakası çizgisel hız değerlerinin, $0.24-0.83 \mathrm{~m} / \mathrm{s}$ değerleri arasında değiştiği görülebilir. Çizelge 2'de hesaplanan değerleri temsil edecek şekilde vargel tezgahının vites kademeleri incelenmiştir. Denemede kullanılan vargel tezgahı üzerinde bulunan vites kollarından $6 \mathrm{hlz}$ kademesi elde edilebilmektedir. Bu kademelerde vargelin geliştirebildiği hız değerleri, gerekli ölçămier yapılarak belirlenmiştir. Pnōmatik makinalar için uygun olabilecek çalişma hızı değerlerini temsil edebilecek, denemelerde kullanilan vargelin çizgisel hiz değerleri, $0.25 \mathrm{~m} / \mathrm{s}, 0.38 \mathrm{~m} / \mathrm{s}, 0.55$ $\mathrm{m} / \mathrm{s}$ ve yüksek bir değer olarak $0.79 \mathrm{~m} / \mathrm{s}$ olarak saptanmıştır.

Çizelge 2. llerleme hızından yararlanılarak elde edilen ekici düzen delikli plakalarının emme yapłığı noktadaki çizgisel hız değerlerì

\begin{tabular}{|c|c|c|c|c|c|c|c|c|c|c|c|}
\hline \begin{tabular}{|c|}
$\mathrm{VM}_{\mathrm{k}}$ \\
$(\mathrm{km} / \mathrm{h})$
\end{tabular} & $\begin{array}{r}V_{M} M_{m} \\
(\mathrm{~m} / \mathrm{s}) \\
\end{array}$ & $\begin{array}{c}n T \\
\text { (d/d) }\end{array}$ & $\begin{array}{l}\text { Sira } \\
\text { Ozeri } \\
\end{array}$ & $\begin{array}{c}\text { Delik } \\
\text { sayis! } \\
\end{array}$ & Tohum & $\begin{array}{c}\mathrm{Z1} \\
\text { (Tek) } \\
\end{array}$ & $\begin{array}{c}Z 2 \\
\text { (Del plaka) }\end{array}$ & $i$ & \begin{tabular}{|c|}
$\mathrm{nD}$ \\
$(\mathrm{d} / \mathrm{d})$ \\
\end{tabular} & $\begin{array}{c}\omega \\
(\mathrm{rad} / \mathrm{s}) \\
\end{array}$ & $\begin{array}{c}\mathrm{V} \\
(\mathrm{m} / \mathrm{s}) \\
\end{array}$ \\
\hline 5 & 1,39 & 44,23 & 15,4 & 30 & Soya, S.pancar & 11 & 15 & 0,73 & 32,4 & 3,40 & 0,39 \\
\hline 6 & 1,67 & 53,08 & 23,1 & 20 & Şekerpancarı & 11 & 15 & 0,73 & 38,9 & 4,07 & 0,47 \\
\hline 7 & 1,94 & 61,92 & & & & 11 & 15 & 0,73 & 45,4 & 4,75 & 0,55 \\
\hline 8 & 2,22 & 70,77 & & & & 11 & 15 & 0,73 & 51,9 & 5,43 & 0,62 \\
\hline 9 & 2,50 & 79,62 & & & & 11 & 15 & 0,73 & 58,4 & 6,11 & 0,70 \\
\hline 5 & 1,39 & 44,23 & 22,5 & 30 & Şekerpancan & 11 & 22 & 0,50 & 22,1 & 2,31 & 0,27 \\
\hline 6 & 1,67 & 53,08 & & & & 11 & 22 & 0,50 & 26,5 & 2,78 & 0,32 \\
\hline 7 & 1,94 & 61,92 & & & & 11 & 22 & 0,50 & 31,0 & 3,24 & 0,37 \\
\hline 8 & 2,22 & 70,77 & & & & 11 & 22 & 0,50 & 35,4 & 3,70 & 0,43 \\
\hline 9 & 2,50 & 79,62 & & & & 11 & 22 & 0,50 & 39,8 & 4,17 & 0,48 \\
\hline 5 & 1,39 & 44,23 & 20,6 & 30 & Misir & 12 & 22 & 0,55 & 24,1 & 2,53 & 0,29 \\
\hline 6 & 1,67 & 53,08 & 30,9 & 20 & Misir, Ayçiçeği & 12 & 22 & 0,55 & 29,0 & 3,03 & 0,35 \\
\hline 7 & 1,94 & 61,92 & 10,3 & 60 & Soya & 12 & 22 & 0,55 & 33,8 & 3,54 & 0,41 \\
\hline 8 & 2,22 & 70,77 & & & & 12 & 22 & 0,55 & 38,6 & 4,04 & 0,46 \\
\hline 9 & 2,50 & 79,62 & & & & 12 & 22 & 0,55 & 43,4 & 4,55 & 0,52 \\
\hline 5 & 1,39 & 44,23 & 36,9 & 20 & Ayçiçeği & 11 & 24 & 0,46 & 20,3 & 2,12 & 0,24 \\
\hline 6 & 1,67 & 53,08 & & & & 11 & 24 & 0,46 & 24,3 & 2,55 & 0,29 \\
\hline 7 & 1,94 & 61,92 & & & & 11 & 24 & 0,46 & 28,4 & 2,97 & 0,34 \\
\hline 8 & 2,22 & 70,77 & & & & 11 & 24 & 0,46 & 32,4 & 3,40 & 0,39 \\
\hline 9 & 2,50 & 79,62 & & & & 11 & 24 & 0,46 & 36,5 & 3,82 & 0,44 \\
\hline 5 & 1,39 & 44,23 & 19,5 & 20 & Misır, Soya & 13 & 15 & 0,87 & 38,3 & 4,01 & 0,46 \\
\hline 6 & 1,67 & 53,08 & & & & 13 & 15 & 0,87 & 46,0 & 4,81 & 0,55 \\
\hline 7 & 1,94 & 61,92 & & & & 13 & 15 & 0,87 & 53,7 & 5,62 & 0,65 \\
\hline 8 & 2,22 & 70,77 & & & & 13 & 15 & 0,87 & 61,3 & 6,42 & 0,74 \\
\hline 9 & 2,50 & 79,62 & & & & 13 & 15 & 0,87 & 69,0 & 7,22 & 0,83 \\
\hline
\end{tabular}




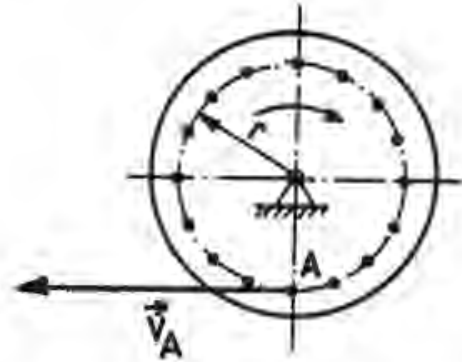

Şekil 4. Delikli plaka üzerindeki deliğin çizgisel hız degerinin gösterimi

Denemeler gerçekleştirilirken;

- Denenecek tohum çeșidi bir yığın oluşturacak şekilde kanala doldurulmuş,

- Delik çapı bilinen delikli plaka takıımıs.

- Vakum sevíyesi ayarlanmiş.

- Vargelín ilerleme hızı ayarlanmıştır. Bu ayar değerlerinde vargelin ileri geri hareket eden kafasına bağlanmış olan ve ucunda delikli plaka takılmıs olan emme borusu tohum yığınına daldırilmıştır. Böylece, tutuima yüksekliği sifır yapilarak, emme yüksekliğinin etkisi yok edilmiștir, ayrıca uygulamada da tohumlar delikli plakadaki deliklerle sürekli temas halindedirler. Emme borusu yığından çıkarıldıktan sonra deneme faktörlerinin olçum yapilan seviyelerine göre tohumun tutulup tutulamaması ve 1 adetten fazla tohum tutulması geliştirilmiş çizelgelere kaydedilmiştir.

Tohumların boyut ozelliklerine bağı olarak, delikte tutulabilmesi için vakum hattına kaçmayacakları en buyauk delik çapına kadar denemeler sürdürülmüştür.

\section{Bulgular ve Tartışma}

Farkli 5 tohumda, tohumlara göre değişen 12 farkiı delik çapında, 6 farkı vakum seviyesinde, 4 farklı delikli plaka çizgisel hızı değerinde tohumların tutulabilme özellikleri, grafiksel olarak değerlendirilmiştir, Elde edilen grafikler, Şekil 5'de gösterilmiştir. Grafiklerdeki koyu renkli alanlar tohumların tek tek tutulduğu bölgeleri, açik renkli alanlar ise ya tohumların hiç tutulmadığı ya da boyük delik çapı değerinde 2 ve daha fazla sayıda tohum tutulduğu bölgeleri göstermektedir.

Öneğin, ayçiçeği tohumlari için verilen ilk sıradaki grafikler incelenirse, $2 \mathrm{~mm}$ delik çapına ilişkin grafikte sol alt bölgede tohumlar tutulmuștur. Onun yanındaki $2.5 \mathrm{~mm}$ delik çapına ilişkin grafikte tek tek tutulan tohumlarda gozle görälür bir artış bulunmaktadır, Ayçiçeğine ilişkin 3, 3.5, $4 \mathrm{~mm}$ delik çapındaki grafikte, denemeye alınan tum vakum ve çizgisel hiz seviyelerinde tek tek tutulmaların gerçekleştiği görólmektedir. Delik çapı $4.5 \mathrm{~mm}$ olduğunda ise dussūk vakum değerlerinde tohumlar tek tek tutulmakta, vakum değeri ve çizgisel hız değeri arttı̆ında ise ikizlenmeler ortaya çıkmaktadır.
Mısır için, $3 \mathrm{~mm}$ delik çapinda çok az tutuimalar gerçekleşmiş, 3.5 ve $4 \mathrm{~mm}$ 'de değişik vakum seviyesi ve delikli plaka çizgisel hızı değerlerinde tutulmalar gözlenmiş, $4.5,5,5.5$ ve $6 \mathrm{~mm}$ delik çaplarında her seviyede tohumlar tek tek tutulmuş, 6.5 ve $7 \mathrm{~mm}$ delik çaplarında ize ikizlemeier başlamiştir.

Şekil 5'e göre; 2.5 ve $3 \mathrm{~mm}$ delik çaplarında belitfi vakum ve delikli plaka çizgisel hızı değerlerinde soya tohumlan tutulamamış, bazı seviyelerde ise tek tutulmalar gerçekleşmiștir. Delik çapi 3.5 ve $4 \mathrm{~mm}$ olduğunda botan seviyelerde tohumiarın tek tutulmasından sözedilebilir. Ancak, delik çapı 4.5 ve 5 mm'ye çıkarıldığında belirli seviyelerde ikizlenmeler ortaya çıkmaktadır.

Daha koçak olan kaplanmış şekerpancarı tohumlarında bätön seviyelerde, 2.5 ve $3 \mathrm{~mm}$ delik çaplarında tek tutulmalar gerçekleşmiştir. Delik çapiarı 2 ve $3.5 \mathrm{~mm}$ olduğunda bazı seviyelerde tek tutulmalar gózlenmiş, bazı seviyelerde ise ya hiç tohum tutulamamış ya da 2 ve daha çok tohum tutulmuştur. Kaplanmamış şekerpancarı tohumlarinda ise, kaplanmış tohumlara göre yalnızca delik çapı değerlerinde bir kayma olmuș, 2-2.5 mm delik çaplarında tam tutulmalar gerçekleşmiştir.

\section{Sonuçlar}

Materyal olarak kullanılan ayçiçeği, soya, misir, kaplanmış ve kapianmamış şekerpancarı tohumlarının, değişik vakum seviyesi, değişik ekici delikli plaka çizgisel hızı ve delik çapı deḡerlerinde gerçekleştirilen denemelerinden şu sonuçlar elde edilmiştir (çizelge 3 ).

Ayçiçeği tohumları, $3.0,3.5$ ve $4.0 \mathrm{~mm}$ delík çaplarında denemeye konu edilen faktörlerin tüm seviyelerinde tutulmuş; bu değerlerin altında bazı vakum ve delikli plaka hızı değerlerinde tutulmamalar da olmuş; daha bayyük çaplarda ise bir adetten fazla tohum tutulmaya başlanmış; çap bayyüdäkçe giderek tohumlar deliklerden içeri girmeye başlamışlardir.

Misir tohumlarında; $4.5,5.0,5.5$ ve $6.0 \mathrm{~mm}$ çaplarda tûm seviyelerde tam tutulma gózlenmiştir. Bunun altindaki ve üzerindeki delik çaplarında bazı seviyeierde hiç tutulamama, ikizleme ya da tohumun delikten geçerek vakum hattına girmesi gibi istenmeyen durumlar ortaya çıkmıştır.

Soyada uygun delik çapları, 3.5 ve $4.0 \mathrm{~mm}$ olarak saptanmıştır:

Kaplanmış şekerpancarı tohumlarında tam tutulmalar, 2.5 ve $3.0 \mathrm{~mm}$ delik çaplarında; kaplanmamiş şekerpancarı tohumlarında ise 2.0 ye $2.5 \mathrm{~mm}$ delik çaplarında gözlenmiştir. şöyledir:

Araştırmada ortaya konulan diger sonuçlar ise 
ACAR, I. A., "Pnömatik hassas ekim makinalarında tohumların tutulmasına etkili bazı parametrelerin etki derecelerinin belirlenmesi"

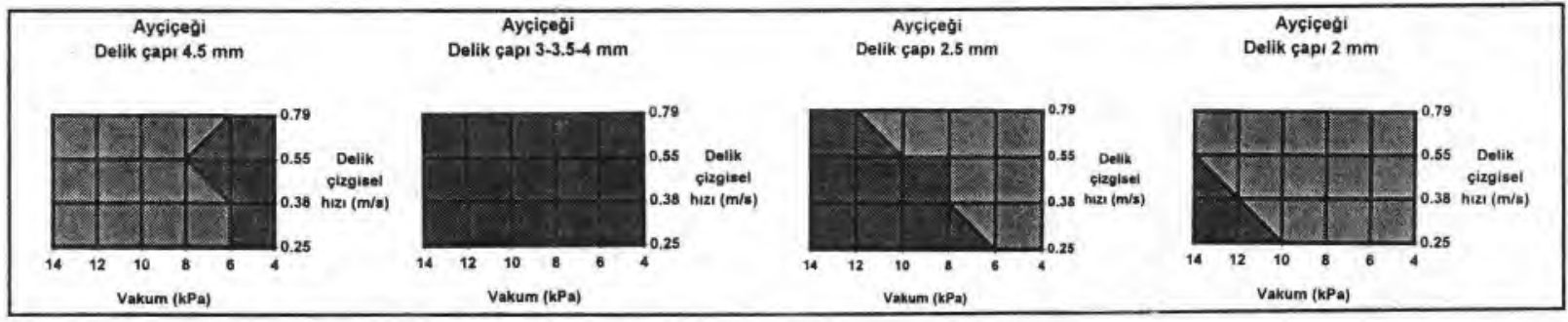
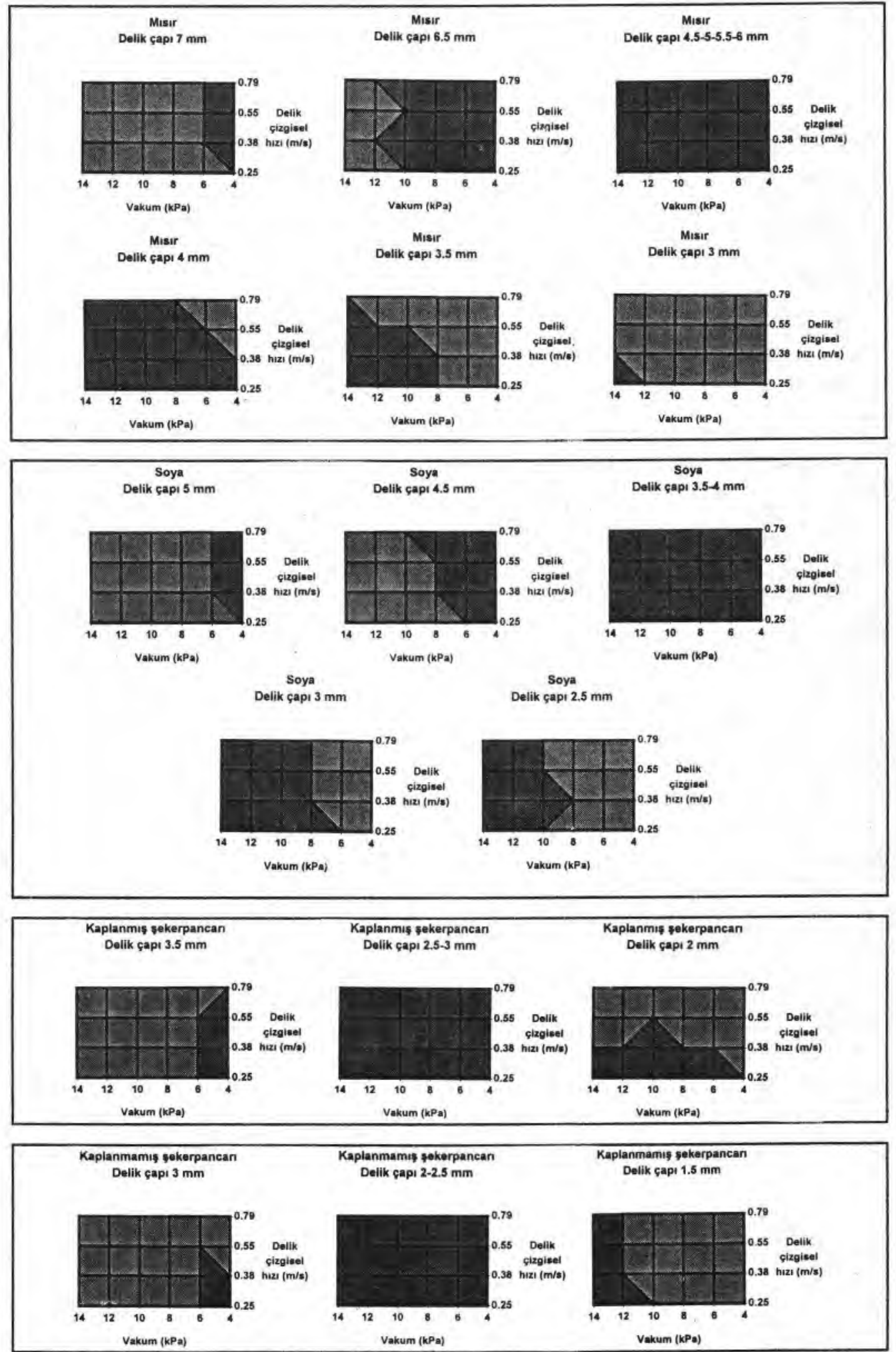

Şekil 5. Denemede kullanılan tohumların delik çapı, çizgisel hız ve vakum değerlerine bağlı olarak tutulabilme özellikleri 
Çizelge 3. Deneme sonuçlarına göre tohumların değişik delik çaplarında tutulmaları

\begin{tabular}{|c|c|c|c|c|c|c|c|c|c|c|c|c|}
\hline \multirow[t]{2}{*}{ Tohumlar } & \multicolumn{12}{|c|}{ Ekici delikli plaka delik çapı değerleri (mm) } \\
\hline & 1.5 & 2.0 & 2.5 & 3.0 & 3.5 & 4.0 & 4.5 & 5.0 & 5.5 & 6.0 & 6.5 & 7.0 \\
\hline Ayçiçeği & & \pm & $\$$ & E & E & D & $\pi$ & & & & & \\
\hline Misir & & & & $\$$ & \pm & $\$$ & $\theta$ & $\theta$ & 항 & $\theta$ & $\pi$ & $\pi$ \\
\hline Soya & & & 2 & 2 & 目 & E & $\pi$ & & & & & \\
\hline Ş.pancarı (kaplanmış) & & $\infty$ & 量 & 田 & $\pi$ & & & & & & & \\
\hline Ş.pancarı kaplanmamıș) & $\$$ & 实 & e & $\pi$ & & & & & & & & \\
\hline
\end{tabular}

E : Denemelere konu edilmiş olan tüm vakum ve çizgisel hız seviyelerinde tohumlar tutuldu.

$\pi$ : Tohumlar deliklerde tek tek tutulmalar yanında faktörlerin belirli seviyelerinde 1 adetten fazla tutulmaya başlandı

๖ : Denemelere konu edilmiş olan vakum ve çizgisel hız seviyelerinin hiçbirinde tutulma gerçekleşmedi.

Her tohum için, o tohumun tutulabildiği uygun delik çapı değerinden daha küçük delik çaplarında, genel olarak, yôksek vakum ve düşuk ekici delikli plaka çizgisel hızı değerlerinde tohumlar deliklerde tek tek tutulabilmektedir. Vakum düşüruldäğünde ve delikli plaka çevre hızı artırıldığında, tohumların deliklerde tutulmalan gũçleşmektedir.

Yığın içerisinden tohumların tutulmasını sağlayan emme ağzı yığına girdiğinde delikte tutulan tohum, yığındaki diğer tohumlar tarafından itilerek bazan tutulma kuweti zayıf olduğunda delikten düșurălmektedir. Kaplanmamış şekerpancarı tchumlarında, üerindeki çıkıntılar nedeniyle tohumlar birbirine tutunabilmekte, bin

\section{Kaynaklar}

Acar, A.I. I, Cilingir, A. Colak, ve R.Öztürk 1993. Küçak tohumlar için tamburlu tip ekici düzen tasarımı. $5^{\text {th }}$ International Congress on Mechanization and Energy in Agriculture, 1114 Oct 1993, Kuşadasi, Türkiye.

Acar, A.I., R. Oztürk, , A. Çolak, ve K.Saçilık 1994. Kạçü taneli tohumlar için bir ekim makinası vantilatörünün temel tasarım parametrelerinin belirlenmesi. Tarımsal Mekanizasyon 15. Ulusal Kongresi, 20-22 Eylül 1994, Antalya.

Anonim 1999. New Holland Trakmak GASPARDO Pnömatik Ekim Makinası Kullanım ve Bakım Kitabı.

Anonim 1987. Tükiye Zirai Donatım Kurumu HASSIA Hava Emişli (Pnömatik) Hassas Ekim Makinası Kullanma, Ayar ve Bakım El Kitabı.

Giannini, G.R., W.J. Chancellor, and R.E.Garrett 1967. Precision planter using vacuum for seed pickup. Transactions of the ASAE, 10 (5), pp: 607610-614, Michigan

Gökçebay, B. 1986. Tarım Makinaları I. Ankara Öniversitesi Ziraat Fakültesi Yayınları: 979, Ankara. dane ağırığı da düşük olduğundan, fazla oranda ikizlemeler ortaya çıkabilmektedir.

Uygulamada ekim işlemi sırasında tohumun fizikomekanik özelliklerine ve doğru ekim tekniğine (ekilecek sıra üzeri uzaklıklara) göre uygun defikli plaka seçilmesi gerekmektedir. Her delik çapı için tohumların tutulmasına uygun vakum ve delikli plaka devir değerleri bulunmaktadır.

Pnömatik etkili hassas ekim makinaları ile çalışılırken, ilerleme hızının, dolayısıyla ekici delikli plaka devrinin arttırıması durumunda, tohumların deliklerde tek tek tutulabilmesi için, vakum değerinin de arttırılması gerekmektedir.

Guarella, P., A. Pallerano, and S.Pascuzzi 1996. Experimental and theoretical performance of a vacuum seeder nozzle for vegetable seeds. J.agric.Engng Res. 64, 29-36.

Hammond, J.E. 1965. Precision vakuum type planter head. USDA-ARS 42-115.

Önal, I. 1995. Ekim, Dikim, Gübreleme Makinalari (II.Basım). Ege Oniversitesi Ziraat Fakültesi Yayınları: 490, İzmir.

Shafii, S., A. Sasao, and S.K.Upadhyaya 1991. Air-jet seed singulation. Transactions of the ASAE, 34 (5), pp: 19731977, Michigan.

Sweetman, I.C. 1957. A suction operated precision planter. N.Z.J. of Science and Technology, A38 (6): 577-582.

Ölger, P., E. Güzel, B. Akdemir, B. Kayışoğlu, Y. Pınar, B. Eker, ve Y.Bayhan 1996. Tarım Makinaları llkeleri. Trakya Universitesi Tekirdağ Ziraat Faköltesi Ders Kitabı No: 29, Tekirdağ. 